\title{
L-carnitine and PPARa-agonist fenofibrate are involved in the regulation of Carnitine Acetyltransferase (CrAT) mRNA levels in murine liver cells
}

Klemens Kienesberger ${ }^{2 \dagger}$, Aniko Ginta Pordes ${ }^{2,3+}$, Thomas Georg Völk² and Reinhold Hofbauer ${ }^{1,2^{*}}$

\begin{abstract}
Background: The carnitine acetyltransferase (CrAT) is a mitochondrial matrix protein that directly influences intramitochondrial acetyl-CoA pools. Murine CrAT is encoded by a single gene located in the opposite orientation head to head to the PPP2R4 gene, sharing a very condensed bi-directional promoter. Since decreased CrAT expression is correlated with metabolic inflexibility and subsequent pathological consequences, our aim was to reveal and define possible activators of CrAT transcription in the normal embryonic murine liver cell line BNL CL. 2 and via which nuclear factors based on key metabolites mainly regulate hepatic expression of CrAT. Here we describe a functional characterization of the CrAT promoter region under conditions of L-carnitine deficiency and supplementation as well as fenofibrate induction in cell culture cells.
\end{abstract}

Results: The murine CrAT promoter displays some characteristics of a housekeeping gene: it lacks a TATA-box, is very GC-rich and harbors two Sp1 binding sites. Analysis of the promoter activity of CrAT by luciferase assays uncovered a L-carnitine sensitive region within -342 bp of the transcription start. Electrophoretic mobility shift and supershift assays proved the sequence element (-228/-222) to be an L-carnitine sensitive RXRa binding site, which also showed sensitivity to application of anti-PPARa and anti-PPARbp antibodies. In addition we analysed this specific RXRa/PPARa site by Southwestern Blotting technique and could pin down three protein factors binding to this promoter element. By qPCR we could quantify the nutrigenomic effect of L-carnitine itself and fenofibrate.

Conclusions: Our results indicate a cooperative interplay of L-carnitine and PPARa in transcriptional regulation of murine CrAT, which is of nutrigenomical relevance. We created experimental proof that the muCrAT gene clearly is a PPARa target. Both L-carnitine and fenofibrate are inducers of CrAT transcripts, but the important hyperlipidemic drug fenofibrate being a more potent one, as a consequence of its pharmacological interaction.

Keywords: L-carnitine, PPARa, Carnitine acetyltransferase, Fenofibrate

\footnotetext{
* Correspondence: reinhold.hofbauer@univie.ac.at

${ }^{\dagger}$ Equal contributors

${ }^{1}$ Centre for Molecular Biology, Department of Biochemistry and Cell Biology,

Max F. Perutz Laboratories, University of Vienna, Dr. Bohrg. 9, Vienna A-1030,

Austria

${ }^{2}$ Department of Medical Biochemistry, Division Molecular Genetics, Max F.

Perutz Laboratories, Medical University of Vienna, Dr. Bohrg. 9, Vienna

Biocenter, A-1030 Vienna, Austria

Full list of author information is available at the end of the article
}

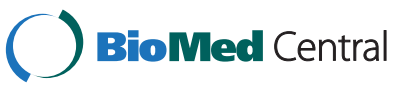

C 2014 Kienesberger et al.; licensee BioMed Central Ltd. This is an Open Access article distributed under the terms of the Creative Commons Attribution License (http://creativecommons.org/licenses/by/4.0), which permits unrestricted use, distribution, and reproduction in any medium, provided the original work is properly credited. The Creative Commons Public Domain Dedication waiver (http://creativecommons.org/publicdomain/zero/1.0/) applies to the data made available in this article, unless otherwise stated. 


\section{Background}

L-carnitine (L-3-hydroxy-4-N - trimethylaminobutyrate) is a low molecular ammonium compound, which is synthesized from the two essential amino acids lysine and methionine mostly in liver and kidney [1-3]. It is an important cofactor for the transport of long chain fatty acids across the mitochondrial membranes into the matrix where they can be broken down by $ß$-oxidation to acetyl-CoA to obtain energy via the citric cycle $[4,5]$. Due to its regulative functions on the acetyl-CoA pools and its transporting features of acyl groups, Lcarnitine covers also a key role in glucose metabolism and assists in fuel sensing [6]. An abnormal increase of intramitochondrial acetyl-CoA concentration in liver cells leads to increased gluconeogenesis, one aspect of diabetes [7]. High levels of acetyl-CoA have also been associated with abnormalities in skeletal muscles of diabetic patients, where insulin seems to be unable to mediate the switch from lipid to glucose metabolism leading to decreased glucose utilization [8].

Carnitine Acetyltransferase (CrAT) is a mitochondrial matrix enzyme, which transfers short acyl groups from acyl-CoA to L-carnitine resulting in an acetylcarnitine-ester [9]. Therefore it defines the equilibrium of acetyl-CoA (+free L-carnitine) and acetylcarnitine (+free CoA) [10]. Highest expression levels of CrAT are reached in muscle cells and testis [9]. Although expression levels are low in liver it exerts a significant metabolic function by regulating acetyl-CoA pools at the crossroads of anabolic and catabolic pathways [11]. Carnitine supplementation promotes CrAT-mediated acetylcarnitine efflux and improves metabolic outcome in obese rodents $[12,13]$. Furthermore the importance of CrAT has been recently underlined by the fact that muscle-specific knock-out mice showed increased metabolic inflexibility, meaning that they failed to adjust appropriately to mitochondrial fuel selection in response to nutritional cues [14]. Another very supportive fact for our study was that NIDDM patients showed decreased levels of CrAT mRNA levels [14]. These findings render CrAT to be an interesting pharmacological target for treatment of NIDDM. L-carnitine itself could be a pharmacological tool since supplementation after artificially induced L-carnitine deficiency induces CrAT expression in a moderate way [15].

Murine CrAT gene (GeneID 12908) had been mapped on chromosome 2 next to the protein phosphatase $2 \mathrm{~A}$, regulatory subunit $\mathrm{B}$ (PR 53) gene (PPP2R4). No detailed promoter studies have been published so far, but PPAR $\alpha$ plays a key role in CrAT transcription control $[16,17]$. So we hypothesized that a cooperative interplay between L-carnitine and PPAR $\alpha$ positively influences CrAT expression.

\section{Results}

L-carnitine and PPARa induce murine CrAT expression

The L-carnitine levels in the FCS after dialysis against phosphate buffered saline for $48 \mathrm{~h}$ dropped significantly from $36 \mu \mathrm{M}$ to $16 \mu \mathrm{M}$ (see Table 1). In a direct consequence the intracellular L-carnitine levels after cultivation in dialyzed FCS were reduced more than $70 \%$ and after L-carnitine supplementation could be restored to more than $70 \%$ of the original level of $973 \mu \mathrm{M}$ L-carnitine (see Table 2). Under these cell culture conditions we performed our L-carnitine deprivation/supplementation studies.

Our first experiments examined the regulation of the murine CrAT gene by L-carnitine and fenofibrate. CrAT mRNA levels were increased by L-carnitine supplementation (for $4 \mathrm{~h}$ ) after artificially induced Lcarnitine deficiency (Figure 1A). Additionally we tested the influence of $80 \mu \mathrm{M} \mathrm{L}$-carnitine on muCrAT mRNA levels up to 48 hours after supplementation. After 4 hours the first peak of CrAT mRNA levels was detected (1.65 fold increase). A second application rate of $80 \mu \mathrm{M} \mathrm{L}$-carnitine was added after $15 \mathrm{~h}$ and lead to even higher CrAT mRNA levels. (2.23 fold after $18 \mathrm{~h}$ ) (Figure 1B). Also the PPAR $\alpha$-agonist fenofibrate induced muCrAT up to 11 -fold (with $40 \mu \mathrm{M}$ fenofibrate) (Figure 1C).

\section{L-carnitine raises PPARa presence in the nucleus}

PPAR $\alpha$ protein levels in the nucleus increase constantly after L-carnitine supplementation (Figure 2A). Already 4 hours after L-carnitine supplementation slightly increased levels of PPAR $\alpha$ levels are detectable in the nucleus ( 1.2 fold) and gets more distinct after longer supplementation periods ( 1.5 fold after 15 hours and 1.7 fold after 24 hours. The western blot presented in Figure 2B shows the almost even induction pattern of CrAT protein levels in TIB-73 cells cultivated in fetal calf serum, dialyzed fetal calf serum and after L-carnitine $(80 \mu \mathrm{M})$ and/or fenofibrate $(40 \mu \mathrm{M})$ supplementation. The cultivation in dialyzed fetal calf serum slightly reduces the TIB73 CrAT protein levels and subsequent L-carnitine does not really influence the steady state CrAT protein. Only fenofibrate is able to increase it distinctly.

Table 1 Serum L-carnitine Levels

\begin{tabular}{llll}
\hline & $\begin{array}{l}\text { Serum L-carnitine } \\
\text { concentration }(\boldsymbol{\mu M})\end{array}$ & SD & p-value \\
\hline (A) Fetal Calf Serum & 36 & \pm 9 & - \\
(B) Dialysed Fetal Calf Serum & 16 & \pm 5 & $\mathrm{p}=0.028$ \\
\hline
\end{tabular}

Measurements of serum L-carnitine concentrations before and after dialysis. For statistical analysis dialysed FCS was compared to non-dialysed FCS (values represent means, $n=3$, (A) vs. (B) $p=0.028$ ). 
Table 2 Intracellular L-carnitine Levels

\begin{tabular}{llll}
\hline & $\begin{array}{l}\text { Intracellular L-carnitine } \\
\text { concentration }(\boldsymbol{\mu M})\end{array}$ & SD & p-value \\
\hline (A) TIB73 in DMEM + 10\%FCS & 973 & \pm 52 & - \\
(B) TIB73 in DMEM + dia.FCS & 265 & \pm 51 & $p<0.001$ \\
(C)TIB73 in DMEM + & 711 & \pm 72 & $p<0.001$ \\
dia.FCS + $80 \mu \mathrm{M}$ L-carnitine & & & \\
\hline
\end{tabular}

Measurements of intracellular L-carnitine concentrations of TIB73 cells under physiological conditions (A), L-carnitine deficiency (B) and supplementation (C). For statistical analysis conditions A and B were compared as well as conditions $B$ and $C$.

(Values represent means, $n=3$; (A) vs. (B) $p<0.001$ and (B) vs. (C) $p<0.001$ ).

\section{L-carnitine increases CrAT promoter activity}

Three luciferase constructs (mCrAT-1, mCrAT-2 and $\mathrm{mCrAT}-3)$ were designed containing different regions of the 5 ' flanking region of the murine CrAT gene (Figure 3). All three constructs were transfected separately into TIB73 murine liver cells and promoter activity was measured after $4 \mathrm{~h}$ (Figure 4 ). mCrAT-2 shows higher promoter activity than mCrAT-3 at all 3 different L-carnitine supplementation levels. Within this construct a RXR $\alpha$, two Sp1, a CAC-binding protein and a PPAR $\alpha$ binding site were identified using the Transfac database via the online-tools TESS and PATCH.

\section{Analysis of the murine CrAT 5' flanking sequence}

The murine CrAT promoter and its putative cisregulatory elements for nuclear factors are depicted in Figure 3. Analysis of the $5^{\prime}$-flanking region of exon 1 revealed several putative transcription factor-binding sites. Most importantly a RXR $\alpha$ element was found at $-228 \mathrm{bp}$ to $-222 \mathrm{bp}$. The CrAT promoter is a TATA-less one with two SP1 binding sites. Further on the $5^{\prime}$ promoter region harbors binding sites for HES-1, CREB, CAC-binding protein and at last a PPAR $\alpha$ site within the first exon.

\section{L-carnitine raises binding affinity of nuclear extracts to RXRa} probe - anti-PPARa antibody abrogates this DNA-protein formation

To gain more insight into the binding affinities of nuclear extracts to different probes representing the putative transcription factor binding sites we performed several EMSAs. Nuclear extracts of TIB-73 cells were prepared after $4 \mathrm{~h}$ of L-carnitine supplementation at different concentrations. EMSA analysis of the DNA probe representing the RXR $\alpha$ binding site revealed increased affinity of nuclear extracts to this ODN with rising L-carnitine concentrations. Additional administration of anti-PPAR $\alpha$ antibody (sc-9000X) directly to the EMSA reaction mix lead to weakening of the band shift signal at $40 \mu \mathrm{M}$ L-carnitine and nearly to extinction of the signal at $80 \mu \mathrm{M}$ L-carnitine (Figure 5A, B). Based on this result we concluded that Lcarnitine influences transcriptional activation via PPAR $\alpha$.

Further on we performed Southwestern Blotting to gain more information about the complexity of the protein factors binding to this specific $\mathrm{RXR} \alpha$ promoter element. We received three distinct signals at $51 \mathrm{kDa}, 70 \mathrm{kDa}$ and $145 \mathrm{kDa}$. A search in the Transfac database via molwsearch (www.gene-regulation.com) presented LXR $\alpha$ and PPAR $\alpha$ as candidate factors for the $51 \mathrm{kDa}$ signal, c-Myb and cMyc as putative factors for the $70 \mathrm{kDa}$ band and Evi-1 for the $145 \mathrm{kDa}$ signal (Figure 6A, B).

\section{Discussion}

No detailed promoter study of the murine CrAT promoter has been published so far. Basically the CrAT gene
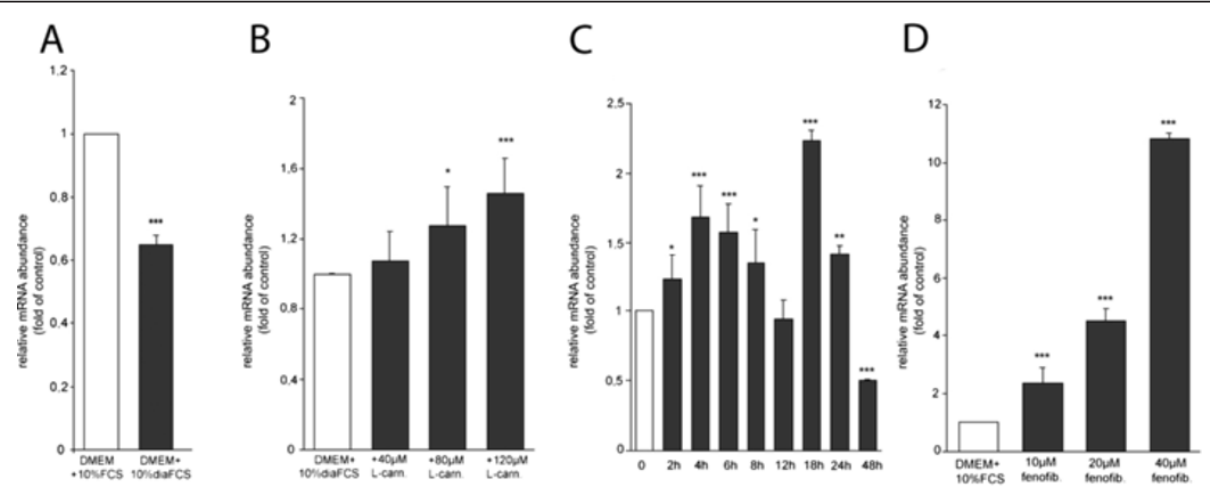

Figure 1 Quantification of CrAT mRNA levels. (A) TIB-73 murine liver cells were cultivated in DMEM and 10\%FCS in comparison to cells treated $24 \mathrm{~h}$ with dialyzed FCS. (B) TIB-73 murine liver cells were grown for $24 \mathrm{~h}$ with dialyzed FCS and supplemented afterwards for 4 hours with L-carnitine (40-120 $\mathrm{MM})$. (C) Following 24 hours of treatment with dialyzed FCS TIB-73 cells were supplemented with $80 \mu \mathrm{M}$ L-carnitine for 2-48 h. A second L-carnitine boost ( $80 \mu \mathrm{M})$ took place after 15 hours. Mean value for $0 \mathrm{~h} \mathrm{~L}$-carnitine suplementation was designated as 1 . Supplemented cultures were compared to non-supplemented control (DMEM + 10\%diaFCS) in B and C. Values represent means \pm SD ( $n=3$ ). Means without asterisk show no statistical significance ( $p>0.05$ ); ( $p$-values of asterisk marked means are as followed: $\left.{ }^{*} p<0.05,{ }^{* *} p<0.01,{ }^{* * *} p<0.001\right)(\mathbf{D})$ TIB-73 cells were grown in DMEM + 10\%FCS for 24 hours and afterwards treated with fenofibrate $(10-40 \mu M)$. Values represent means \pm SD $(n=3)$. Supplemented cultures were compared to physiological control. ${ }^{* * *} p<0.001$. 
A

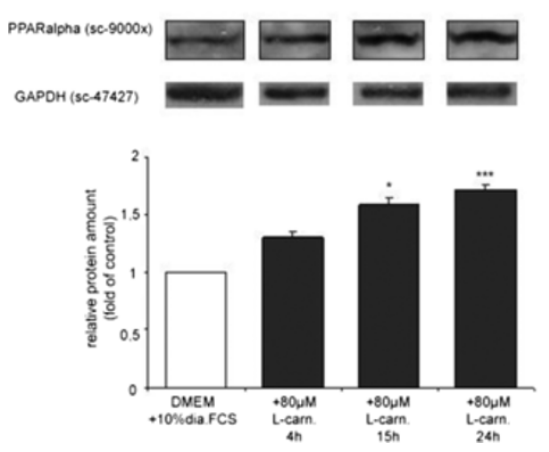

B

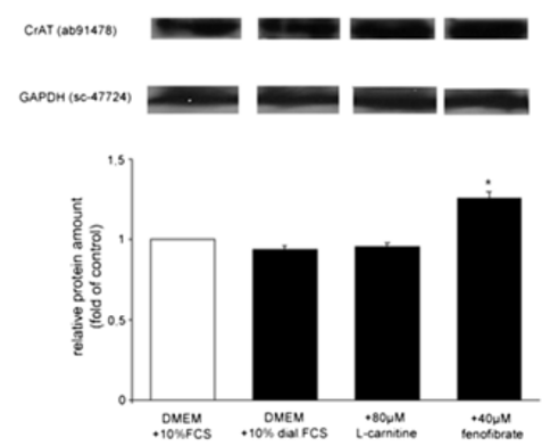

Figure 2 PPARa Western blot from nuclear extracts of TIB-73 cells. (A) Cells were treated as described in Figure 1. Nuclear extracts were prepared after 4, 15 and 24 hours of L-carnitine supplementation; values are mean \pm SD, $n=3,{ }^{*} p<0.05$ and ${ }^{* * *} p<0.001$ vs. DMEM $+10 \%$ dia.FCS (B) CrAT Western blot from whole cell extracts of TIB-73 cells. Cells were treated as described in Figure 1. values are mean \pm SD, $n=3$, *p $<0.05$ vs. DMEM + $10 \%$ dial.FCS.

exhibits the typical characteristics of a housekeeping promoter: it harbours no TATA box, is GC rich and has two Sp1 binding sites. The distance to the transcriptional start of the opposing PPP2R4, which is encoded on the complementary strand, is only $586 \mathrm{bp}$. This leads to the reasonable postulation that this promoter very likely is a bi-directional one. For the human PPP2R4 promoter it could be shown that Yin-yang 1 (YY-1) is essential for core promoter activity and that it is a p53 target gene $[18,19]$. By applying TESS we could find three YY-elements, two at positions -52 to -44 and +27 to +35 relative to the PPP2R4 transcription start and a third one already in the first exon of the PPP2R4 gene. These putative YY-binding sites very likely represent the murine equivalents to the human promoter (Figure 3).

One aim of our work was to identify inducers of transcriptional activation of CrAT. As depicted in Figure 1 L-carnitine and fenofibrate are such transcriptional activators. L-carnitine induces CrAT and other members of the "acylcarnitine shuttle system" like CPT1a and b, as well as CPT2 transcription levels in the human system similar to mice [15]. Beyond that, in a parallel chip-screen study performed by our lab, we observed that hundred of genes throughout the whole genome
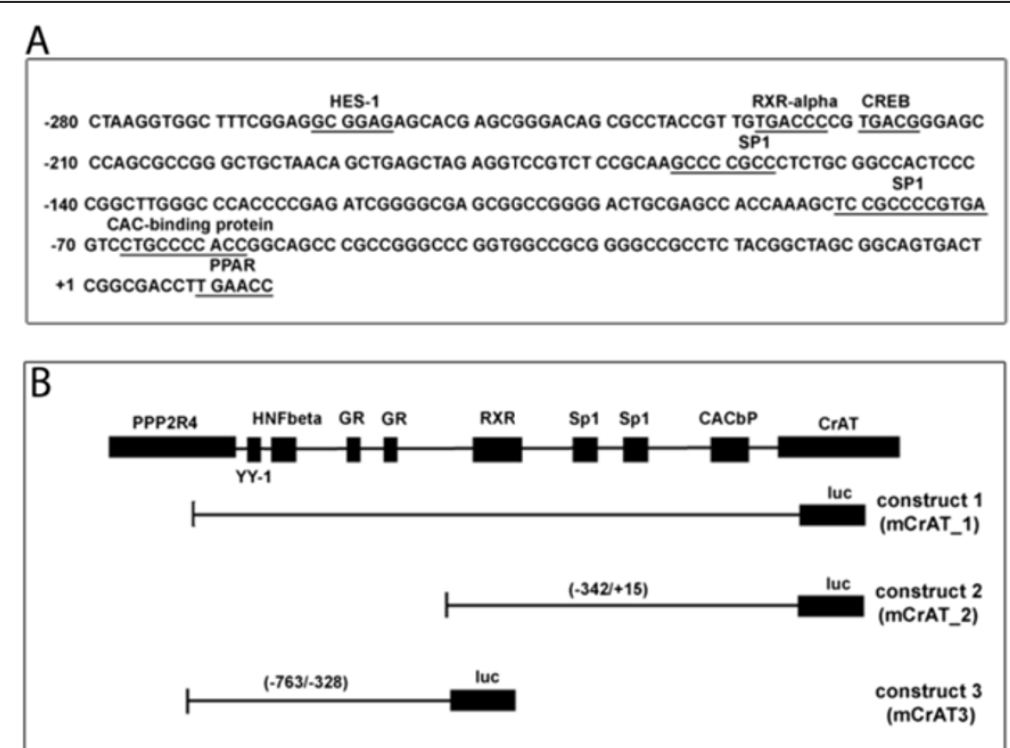

Figure 3 Organisation of the murine CrAT promoter. (A) Presentation of the $5^{\prime}$ flanking sequence of the murine CrAT gene. Consensus binding sites are underlined. (B) Schematic structure of the murine CrAT promoter with putative binding sites. mCrAT-1 represents the construct for luciferase-assays ranging from $-342 \mathrm{bp}$ to $+15 \mathrm{bp}$ and $\mathrm{mCrAT}-2$ from -763 to $-328 \mathrm{bp}$. The artificial promoter construct mCRAT-1 contained the RXR-box, two Sp1 elements and one CACbP region in front of the luc-gene of the PGL2-basic luciferase reporter vector. The promoter construct mCRAT-2 contained three YY-1 sites, two GR1 elements and a HNF 3 box in front of the reporter luc-gene. 


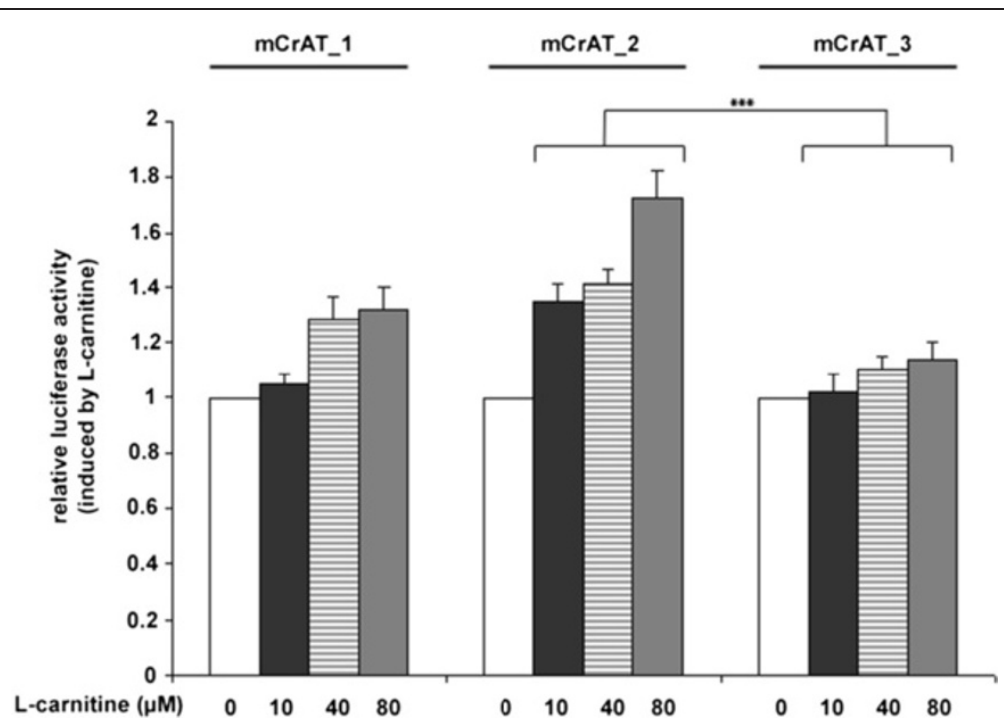

Figure 4 Activity of different CrAT promoter constructs after supplementation with L-carnitine. TIB-73 cells cultured in medium containing 10\% FCS to cause artificial L-carnitine deficiency were cotransfected either with mCrAT-1, mCrAT-2 or mCrAT-3 together with pCMV-ßgal and supplemented with increasing concentrations of L-carnitine for 4 hours. Luciferase activity was normalized for ß-gal activity. Data represent the mean $\pm S D, n=4$; the mean value for non-supplemented cultures is designated as 1. Comparison of mCrAT-2 and mCrAT-3 constructs at all 3 supplementation levels for 10,40 and $80 \mu \mathrm{M} \mathrm{L}$-Carnitine revealed ${ }^{* *} p$-values $(p<0.001)$ indicated with parentheses. A Kruskal-Wallis test for all three constructs resulted in slightly less significant $p$-values ( $p=0.094$ for $10 \mu \mathrm{M} L$-carnitine, $p=0.0002$ for 40 and $80 \mu \mathrm{M} \mathrm{L-carnitine)}$.

are transcriptionally in- or decreased by L-carnitine, underlining the importance of this metabolite [20]. In case of the murine CrAT we observed a rather moderate increase of mRNA levels (up to 1.8 fold) after $4 \mathrm{~h}$ of L-carnitine supplementation following artificially induced L-carnitine deficiency. The above-mentioned opposing PPP2R4 gene is transcriptionally induced by L-carnitine and fenofibrate very similar to the CrAT gene as shown in the human liver cell line Hep G2 (see Additional file 1: Figure S1), which is another argument for the bi-directionality of the promoter.

The important hyperlipidemic drug fenofibrate is a much more potent inducer of CrAT transcription levels (up to 11-fold after 3 hours of fenofibrate treatment). But no firm indications exist for a PPRE element in CrAT promoter from bioinformatical analysis. This was also
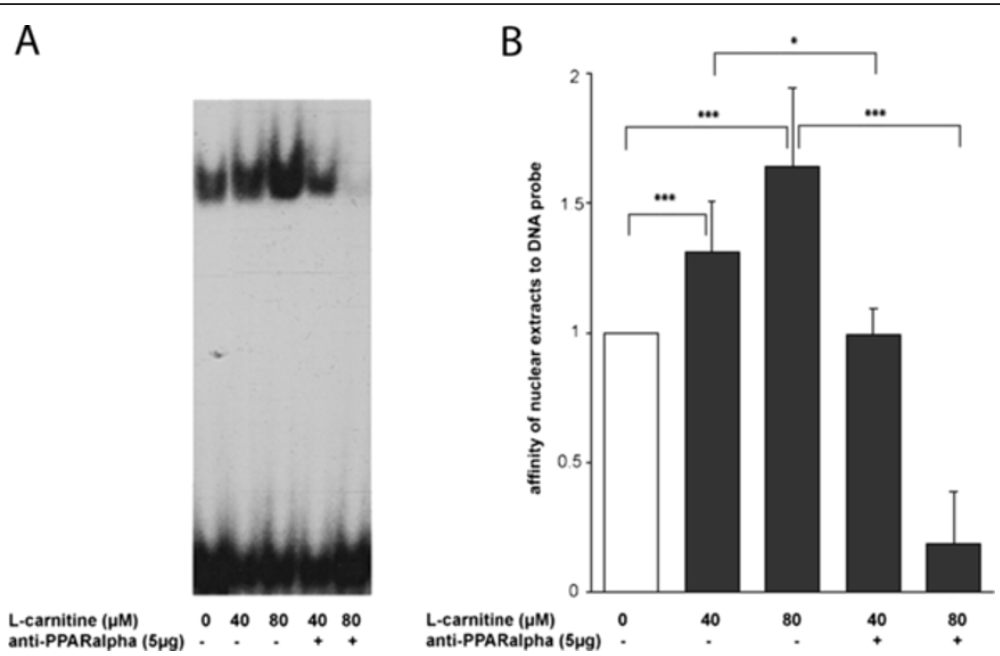

Figure 5 Protein complexes binding to RXRa binding site at the CrAT promoter. (A) EMSA. Nuclear extracts from TIB-73 cells supplemented with increasing concentrations of $\mathrm{L}$-carnitine were incubated with $\mathrm{Y}^{-32} \mathrm{P}$-labeled oligonucleotides representing the RXRa-binding site with anti-PPARa as indicated. (B) Histogramm of the denstitometrical scan of the EMSA presented in A. Values are mean $\pm S D, n=3,{ }^{* * *} p<0.001$ and ${ }^{*} p<0.05$ vs. Corresponding supplementation levels are indicated with parentheses and asterisks on top to indicate the statistical significance of the p-values. 

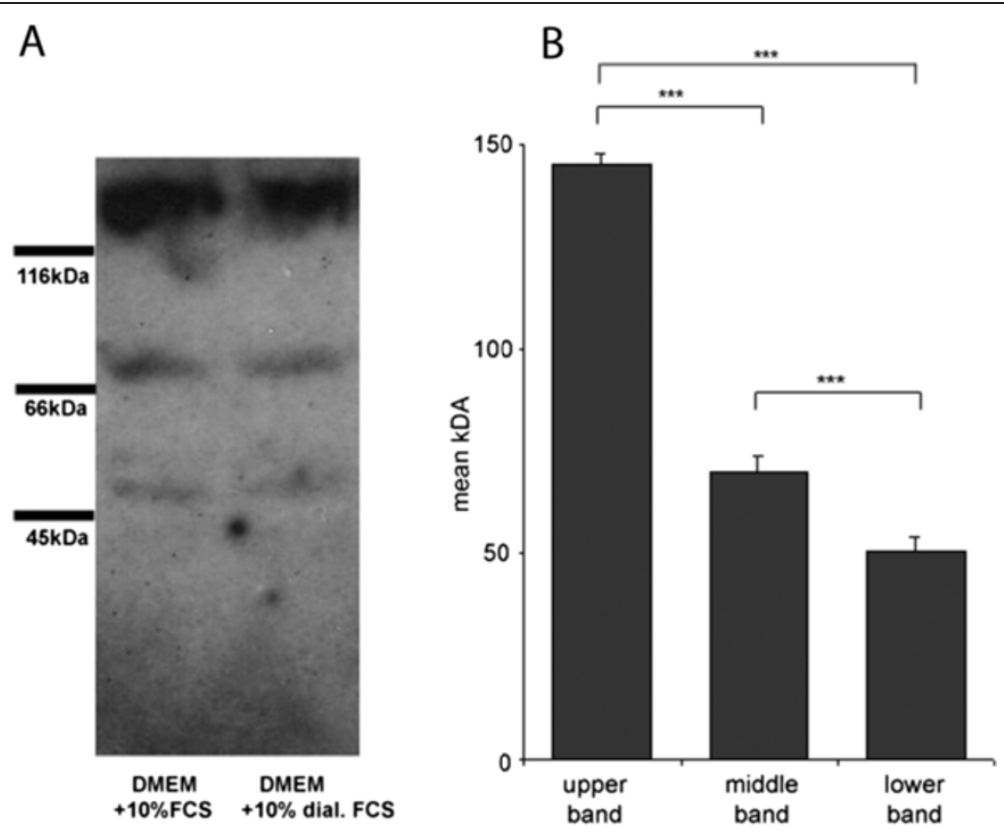

Figure 6 South-Western Blot of nuclear extracts from TIB-73. (A) cells cultivated in DMEM $+10 \%$ FCS and DMEM + $10 \%$ dialyzed FCS. Marker proteins adjacent to the blot indicate the size range $116 \mathrm{kD}, 66 \mathrm{kD}$ and $45 \mathrm{kD}$. (B) Graphical analysis of 3 distinct bands in kDa (145 \pm 3 , $70 \pm 4,51 \pm 4$ ), values are mean $\pm S D, n=4 .{ }^{* * *} p<0.001$.

assumed for CPT1a and CPT2 [10], but for the latter PPREs could finally be defined [21]. CPT2 hosts a special PPRE, namely only one half proportion with perfect consensus sequence (TGACCT) [22]. Our results undoubtedly prove that muCrAT is a PPAR $\alpha$ target, as it has also been indicated in experiments with PPAR $\alpha$ knock-out mice $[16,17]$.

By reportergene assays we were able to define an Lcarnitine sensitive region within 342 nt upstream the transcription start (Figure 3B and 4). Within this sequence many different putative binding sites for nuclear factors were predicted in silico. Our band shift experiments clearly revealed one RXR $\alpha$ element to be sensitive to Lcarnitine supplementation.

Based on our data we propose the sequence TGACC CCGTGACGG at -238 upstream the transcription start to be a possible L-carnitine sensitive RXR $\alpha /$ PPAR $\alpha$ binding site. Band shift assays performed with an oligo desoxynucleotide carrying only the $5^{\prime}$-half of this sequence element showed sensitivity to L-carnitine supplementation. At least the sequence box TGACC is present in the CrAT L-carnitine binding site, therefore we propose in analogy to the CPT2 gene this sequence element being a further imperfect but functional PPRE site. Increasing Lcarnitine levels lead to enhanced binding affinity of nuclear extracts. Interestingly the application of anti-PPAR $\alpha$ to the band shift reaction mix lead to a mitigation of the band shift signal. With increasing L-carnitine supplementation levels the band shift signal almost disappeared, indicating the interference of anti-PPAR $\alpha$ with the DNA- protein complex. Such fading out effects have been observed before and were accepted as an experimental proof for a supershift [23]. To rule out that this explicit attenuation effect was an unspecific one, caused by the use of antibodies in general, Supershift assays were performed with antibodies against several candidates of nuclear receptors (see Additional file 1: Figure S2). These validation experiments did not result in any significant changes of the DNA-protein formation except for PPAR $\alpha$. Therefore this effect had to be qualified as a specific interaction.

In addition to this effect we were able to reveal an additional close connection between the PPAR-system and Lcarnitine. Transcription levels of PPAR-binding protein, PPARbp, are also inducible by L-carnitine. Chip screen experiments as well as quantitative PCR also provided experimental proof for this effect [20]. Li JL et al. found experimental proof for an interaction of PPAR $\alpha$ and Lcarnitine as a protective response to oxidative stress [24]. This finding provides additional support to our observations that L-carnitine shows cooperativeness with the PPAR-system. This supposition is strengthened by the results of the Western blot depicted in Figure 2A: Lcarnitine supplementation leads to increased levels of PPAR $\alpha$ in the nucleus. Obviously increased L-carnitine levels foster the translocation of PPAR $\alpha$ into the nucleus. It is of fundamental nutrigenomic importance that RXR $\alpha /$ PPAR $\alpha$ heterodimers are positively regulating transcription rates of fatty acid degradation genes as counterparts to LXR $\alpha$ and SREBP1-c, factors which mostly induce anabolic acting fatty acid synthesis genes $[25,26]$. 
Carnitine Acetyltransferase is a central regulator of intramitochondrial acetyl-CoA pools. The latter holds a prominent position in intermediary metabolism as the universal end product of fatty acid, glucose and amino acid oxidation [12,14]. Acetyl-CoA excess leads to blockage of the TCA cycle and subsequently to accumulation of short carbon compounds, which are further on used for gluconeogenesis in liver [7,27]. This is besides insulin resistance another factor of the pathogenesis of NIDDM [28].

Recently the pivotal role of CrAT in acetyl-CoA metabolism was confirmed since experiments with $\mathrm{CrAT}^{\mathrm{M}-/-}$ knock-out mice showed that absence of CrAT leads to accumulation of medium and long chain acylcarnitines in muscles and subsequently to glucose intolerance via overloaded mitochondria [14]. These findings indicate a possible positive effect of L-carnitine and fenofibrate in the regulation of glucose homeostasis via direct transcriptional activation of CrAT, the first due to a metabolic interaction and the latter based on its pharmacology. Singular and combined administration of these two compounds should be evaluated in controlled clinical trials in order to verify our findings in vivo.

The interaction of L-carnitine and PPAR $\alpha$ as we could show is of transcriptional importance. Therefore the growth condition where this collaborative interplay is able to trigger the genome deserves deeper investigation. L-carnitine could already be identified as a nutritional modulator of glucocorticoid receptor functions [29]. In our electrophoretic mobility assays we also observed a slight induction at one of the glucocorticoid responsive elements (GRE) at position -421 to -396 of the CrAT promoter, after Lcarnitine supplementation, but to a much lesser extend as at the RXR $\alpha / P P A R \alpha$ binding site (see Additional file 1: Figure S3). Thus possible interactions of L-carnitine with other nuclear receptors like PPAR $\alpha$ and GRE and its molecular basis are worthwhile being investigated in the future.

\section{Conclusions}

Based on our investigations we could present a complete study of the murine CrAT promoter and provide strong evidence for a cooperative interplay of L-carnitine and PPAR $\alpha$ for its transcriptional regulation, which undoubtedly is of nutrigenomical importance. Reportergene and electrophoretic mobility assays located a L-carnitine sensitive region within 342 nt upstream the transcription start, that contains one RXR $\alpha /$ PPAR $\alpha$ element which is directly responding to L-carnitine supplementation. Super shift assays performed with a polyclonal antibody demonstrated that the muCrAT gene is a PPAR $\alpha$ target. These evidences are strengthened by our findings that transcription levels of the PPAR-binding protein (PPARbp) are also inducible by L-carnitine. A direct comparison of L-carnitine with the drug fenofibrate revealed, both are inducers of CrAT transcripts, with one implication that the hyperlipidemic drug fenofibrate exerted a more pronounced effect, based on its pharmacological interaction. Within the investigated CrAT promoter sequence a variety of different putative binding sites for nuclear factors were predicted in silico and verified by experimental approaches. Thus possible interactions of L-carnitine with other nuclear receptors like PPAR $\alpha$ and GRE and its molecular basis are worthwhile being investigated in the future. We also could append facts for the bidirectional function of the CrAT promoter in conjunction with the opposing PPP2R4 gene.

\section{Methods}

\section{Cell culture}

The normal embryonic murine liver cell line BNL CL. 2 $\left(\right.$ ATCC $^{\oplus}$ TIB $^{-7 \mathrm{~m}}$ ) was grown at $37^{\circ} \mathrm{C}, 7.5 \% \mathrm{CO}_{2}$ in DMEM supplemented with $10 \%$ fetal calf serum (Sigma Aldrich) and $1 \%$ antibiotics (30 mg/l penicillin, $50 \mathrm{mg} / \mathrm{l}$ streptomycin sulphate). For the experiments cells were either kept in DMEM containing $10 \% \mathrm{FCS}$ or dialyzed $10 \%$ FCS (dialysis was performed against 1xPBS for $48 \mathrm{~h}$ with five buffer changes). L-carnitine (LONZA) and fenofibrate (Lannacher Heilmittel) were added to the culture medium to obtain defined final concentrations as indicated in the experiments.

For reporter gene assays TIB-73 cells grown in 6-well plates were transiently co-transfected with the luciferase reporter constructs $\mathrm{mCrAT}-1, \mathrm{mCrAT}-2$ or $\mathrm{mCrAT}-3$ (described in the promoter construct section) as well as with the $ß$-galactosidase ( $ß$-gal) expressing vector pCMV-ßgal (CLONTECH) for normalization of transfection efficacies.

DNA $(0,4 \mu \mathrm{g}$ pCMV-ßgal and $2 \mu \mathrm{g}$ of the respective luciferase reporter construct) was mixed with $150 \mathrm{mM}$ $\mathrm{NaCl}$ in a total volume of $100 \mu \mathrm{l}$ for each well. Polyethylenimine (PEI Sigma, 18,5 $\mu \mathrm{l}$ for each well) was mixed with $150 \mathrm{mM} \mathrm{NaCl}$ in a total volume of $100 \mu \mathrm{l}$ for each well. The solution was slowly added to the DNA solution to ensure proper formation of DNA/ PEI-complexes, mixed and left at room temperature for $20 \mathrm{~min}$. $200 \mu \mathrm{l} \mathrm{DNA} / \mathrm{PEI}$ mix was added to each well and the cells were kept at serum free conditions for $\sim 4$ hours.

Afterwards, the cells were washed with DMEM and were allowed to grow in DMEM supplemented with $10 \%$ dialyzed FCS and antibiotics for 24 hours. After an additional medium change and cultivation for further 4 hours the cells were treated with various concentrations of Lcarnitine $(10 \mu \mathrm{M}, 40 \mu \mathrm{M}, 80 \mu \mathrm{M})$ and incubated with and without L-carnitine for additional 4 or 24 hours.

\section{L-carnitine assay}

To determine the intracellular L-carnitine levels induced by our cell culture conditions as well as the L-carnitine 
concentrations in the fetal calf serum (dialyzed/normal) employed in the cell culture the L-carnitine colorimetric/ fluorometric assay kit (BioVision) was used. TIB-73 were grown under the conditions described above and $10^{6}$ cells were homogenized in $100 \mu \mathrm{l}$ assay buffer exactly as described in the user manual provided by the vendor. In the case of the fetal calf serum $2 \mu \mathrm{l}$ and $10 \mu \mathrm{l}$ aliquots were subjected the same assay procedure. Since the enzyme based assay is very sensitive to contaminating protein levels all samples were treated with $4 \mathrm{M} \mathrm{HClO}_{4}$ and neutralyzed with $2 \mathrm{M} \mathrm{KOH}$. After centrifugation to remove the precipitated proteins samples were drawn and correlated with an L-carnitine standard curve.

\section{Quantitative real-time PCR}

Total RNA was isolated from cells using Qiagen RNeasy Mini Kit according to the manufacturer's protocol. RNA concentration and purity were estimated from the optical density at 260 and $280 \mathrm{~nm}$ using a NanoDrop spectrophotometer (Thermo Scientific). Three micrograms of RNA were converted to cDNA using RevertAid Reverse Transcriptase (Thermo Scientific) and oligo $(\mathrm{dT})_{18}$ primers. Concentration of primers in each sample was $0.5 \mu \mathrm{M}$ and $2 \mu \mathrm{l}$ of a 1:100 dilution of each cDNA was used as template. Parameters for real-time PCR were as follows: $95^{\circ} \mathrm{C}$ for $10 \mathrm{~min}, 45 \mathrm{cycles}$ of $95^{\circ} \mathrm{C}$ for $30 \mathrm{sec}, 61^{\circ} \mathrm{C}$ for $15 \mathrm{sec}, 72^{\circ} \mathrm{C}$ for $40 \mathrm{sec}$. Amplification of target gene was detected by SYBR Green (Roche LightCycler FastStart DNA Master SYBR Green) and analyzed by ${ }^{\Delta \Delta_{-}}$CT method. $\beta$-actin was used as reference gene. Following primers were used for real-time PCR to quantify mRNA levels: $C r A T$ Ps: 5'GCTCAGCCTCCATAGACTCG-3', Pas:5' -AGCAATG GCGTAAGAGGTGT-3'; mu- $\beta$-actin Ps:5'-GCGTGAC ATCAAAGAGAAG-3', Pas:5'-AGGAGCCAGAGCAG TAATC-3';

Promoter constructs, transfection and reporter gene assays A genomic DNA-fragment from the complete murine CrAT promoter was generated by PCR amplification. Two primers were designed GP1s 5' CTCAATGTTCACCCCGCAGC 3' and GP1as 5' CAGAGAGGACAGGAGCTCAC 3 ' defining a $1433 \mathrm{bp}$ fragment. DNA from a mouse genomic library (3 T6 fibroblasts) served as a template. The purified PCR-generated promoter fragment was ligated into a $\operatorname{pBSK}(-)$ vector, subsequently the CrAT promoter DNA fragment in the proper orientation was digested with HindIII and subcloned into the Hind III linearized pGL2basic reporter gene expression vector (Promega), the resulting plasmid clones were analyzed by restriction digestion and sequence analysis. For transfection into mammalian host cells two constructs were established: The construct pGL2-mCrAT-1 was generated with primers GP1s 5'CTCAATGTTCACCCCGCAGC-3' and mCrAT-1as 5'GGTTCTAGGTTCAAGGTCGC-3' included the promoter fragment $(-763 /+15)$. The second construct pGL2-mCrAT2, generated with primers mCrAT2s 5'-GAGTGACGTTC AAGGACACC $-3^{\prime}$ and mCrATlas 5'-GGTTCTAGGT TCAAGGTCGC $-3^{\prime}$ carried the promoter segment $(-342 /+15)$. The third construct pGmCrAT-3, generated with primers GP1s 5' -CTCAATGTTCACCCC GCAGC-3' mCrAT3as 5'-GTCCTTGAACGTCACTCTAGG -3 'contained the promoter segment $(-778 /-328)$.

After the given time points (described above) the cells were harvested, transferred to a microfuge tube, followed by two rounds of freeze - thaw circles with liquid nitrogen versus $37^{\circ} \mathrm{C}$ to ensure complete lysis. The cell lysate was centrifuged at $15.000 \mathrm{rpm}, 4^{\circ} \mathrm{C}$ for $3 \mathrm{~min}$ and the supernatant was transferred to a fresh microfuge tube. $200 \mu \mathrm{l}$ cell extract was mixed with $16 \mu \mathrm{l}$ luciferin (Applichem), $4 \mu \mathrm{l}$ ATP $(0,1 \mathrm{M})$ and $1 \mu \mathrm{l}$ DTT $(1 \mathrm{M})$, vortexed and the luciferase activity in each lysate was measured by a Berthold LB953 luminometer.

\section{In silico analysis of mouse CrAT promoter and 5'UTR for putative nuclear factor binding sites}

To identify putative binding sites of transcriptional active nuclear factors in the mouse $\mathrm{CrAT}$ promoter $850 \mathrm{~kb}$ of the $5^{\prime}$ flanking region of mouse $C r A T$ from -700 to +150 relative to the transcription start were analysed using the online tools TESS (http://www.cbil.upenn.edu/cgi-bin/ tess/tess) and PATCH (http://www.gene-regulation.com/ cgi-bin/pub/programs/patch/bin/patch.cgi).

\section{Electrophoretic mobility shift assay (EMSA)}

Nuclear extracts were prepared from $2 \times 10^{6}$ TIB-73 cells after treatment with or without dialyzed FCS and in presence or absence of L-carnitine $(40-120 \mu \mathrm{M})$ or fenofibrate $(10-40 \mu \mathrm{M})$ after an established protocol [30]. Proteinase inhibitors (Complete Proteinase Inhibitor Mix, Roche) were added according the manufacturer's protocol. Complementary synthetic oligonucleotides corresponding to the RXR binding site in the CrAT promoter were obtained from VBC Biotech (Vienna, Austria) (fwd 5' -AGCGCCTACCGTTGTGACCCCG-3; rev 5'-CGGGG TCACAACGGTAGGCGCT-3') Double stranded oligonucleotides were labeled with $\gamma^{-}{ }^{32} \mathrm{P}$-ATP by T4 polynucleotide kinase (PNK) reaction. The protein-DNA binding mixtures contained labelled probe, nuclear extracts, sonicated salmon sperm DNA as unspecific competitor, $4 \%$ glycerol, $20 \mathrm{mM}$ TRIS pH $8,60 \mathrm{mM} \mathrm{KCl}, 5 \mathrm{mM} \mathrm{MgCl} 2,500 \mu \mathrm{g} / \mathrm{ml}$ BSA. Binding reactions were incubated for $30^{\prime}$ to $1 \mathrm{~h}$ and then resolved in $5 \%$ non-denaturating acrylamide gels in $1 x$ TBE buffer. Electrophoresis was carried out at $120 \mathrm{~V}$ for $360 \mathrm{~min}$ at $4^{\circ} \mathrm{C}$. For supershift analysis antibody solution (anti-PPAR $\alpha$, sc-9000, Santa Cruz Biotechnology) was added after $15^{\prime}$ of preincubation of nuclear extracts with oligonucleotides. 


\section{Western blot analysis}

PPAR $\alpha$ protein levels from nuclear extracts were analysed by Western blot. Nuclear extracts were prepared after an established protocol as described above. Aliquots containing $25 \mu \mathrm{g}$ of nuclear extract were loaded on to a 10\% SDS polyacrylamid gel. After electrophoresis proteins were transferred to a nitrocellulose membrane. The membrane was probed with antibodies against PPAR $\alpha$ (sc-9000, Santa Cruz Biotechnology) and GAPDH (sc-47724, Santa Cruz Biotechnology). In the case of the CrAT western blot $10 \mu \mathrm{g}$ whole cell protein extracts were separated on $12 \%$ SDS polyacrylamid gels and probed with CrAT antibody (Abcam ab91478) and GAPDH (sc-47724, Santa Cruz Biotechnology). The membranes were then processed with HRP conjugated secondary antibodies specific for the appropriate species. Proteins were visualized with Western Lightning ECL kit (Perkin Elmer). The statistical analyses were carried by SPSS software (IBM) using the $t$-test subroutine for independent samples (student's $T$ test) to calculate the p-values given in the figure legends. In the case of Figure 4 we performed a Kruskal-Wallis test with GraphPad Prism (GraphPad Software Inc.).

\section{Southwestern analysis}

For southwestern analysis nuclear extracts and oligonucleotides were prepared as described above. Protein samples were separated by SDS-PAGE and then transferred to nitrocellulose membrane at $110 \mathrm{~V}$ for $90 \mathrm{~min}$ at $4^{\circ} \mathrm{C}$. Blotted proteins were renatured in 1xTNED buffer (10 mM TRIS pH 7.5, $50 \mathrm{mM} \mathrm{NaCl,} \mathrm{0,1} \mathrm{mM} \mathrm{EDTA,}$ $1 \mathrm{mM}$ DTT) with $5 \%$ skim milk for $24 \mathrm{~h}$. The membrane was incubated with $\gamma^{-32} \mathrm{P}$-ATP marked oligonucleotides in 1 xTNED with $2.5 \%$ skim milk for another $24 \mathrm{~h}$. Blot was exposed to chemiluminescent sensitive films visualized via autoradiography. Protein size was determined and further on analyzed via molwsearch using Transfac database (http://www.gene-regulation.com/cgi-bin/pub/ programs/molwsearch/molwsearch.cgi).

\section{Additional file}

Additional file 1: Figure S1. GPCR of human PPP2R4 from the human liver cell line HepG2: (A) cells were treated $24 \mathrm{~h}$ with dialyzed FCS and supplemented afterwards for 4 hours with L-carnitine $(80 \mu \mathrm{M})$. Values show mean $\mathrm{SD}, \mathrm{n}=4$, ${ }^{* * *} \mathrm{p}<0.001$ vs. DMEM $+10 \%$ FCS. (B) Cells were grown in DMEM + 10\%FCS for 24 hours and afterwards treated with fenofibrate $(10-40 \mu M)$ for four hours. Values represent means $\pm S D(n=4)$. Supplemented cultures were compared to physiological control (DMEM + $10 \%$ FCS) ${ }^{* * *} \mathrm{p}<0.001$. Methods: Human liver cell line HepG2 was treated as described in the methods section for TIB-73 cells. For quantitative PCR given protocols as described in the methods sections were followed. Following primers were used: PPP2R4 Ps: 5'CAAGAGTGAAAGGCGAGACG3', Pas:5'CCATGTCTGGAACTGTGTGG'; ß-actin Ps: 5'GATGAGTATGCCTGCCGT GTG3', Pas: 5'TCAACTGGTCTCAA-GTCAGTG3'. Figure S2. Electrophoretic mobility super shift assay with anti-RXRa and anti-PPARY: Nuclear extracts from TIB-73 cells supplemented with increasing concentrations of Lcarnitine were incubated with -32P-labeled oligonucleotides representing the RXRa-binding site with anti-RXRa and anti-PPAR as indicated. No mitigation effect was observable as seen with anti-PPARa antibodies in Figure 5. Figure S3. Electrophoretic mobility shift assay of one of the CrAT promoter GR-binding sites: Nuclear extracts from TIB-73 cells supplemented with increasing concentrations of L-carnitine were incubated with a -32Plabeled oligonucleotide representing the GR-binding site sense: 5' GTCA ACAGTTGTGTTCTCCTGCCATTC3'.

\section{Competing interests}

The authors declare that they have no competing interests.

\section{Authors' contributions}

KK and AGP carried out the sampling, molecular biology, the statistical and software driven analysis of the data and participated in drafting the manuscript and the figures. TV supported the molecular biology and the electrophoretic mobility shift assays. $\mathrm{RH}$ planned the study and supervised the experiments, participated in the sampling and finalized the illustrations and the manuscript. All authors read and approved the final manuscript.

\section{Acknowledgements}

We want to thank Lonza GmbH for providing us with L-carnitine tartrate. KK and the project were supported by the Hochschuljubiläumsstiftung of the City of Vienna. AGP was supported by the Herzfeldersche Familienstiftung. We are grateful to Thomas Sauer for technical assistance and Johann Rotheneder for helpful suggestions with the electrophoretic mobility shift experiments and Helmuth Haslacher for statistical advice.

\section{Author details}

${ }^{1}$ Centre for Molecular Biology, Department of Biochemistry and Cell Biology, Max F. Perutz Laboratories, University of Vienna, Dr. Bohrg. 9, Vienna A-1030, Austria. ${ }^{2}$ Department of Medical Biochemistry, Division Molecular Genetics, Max F. Perutz Laboratories, Medical University of Vienna, Dr. Bohrg. 9, Vienna Biocenter, A-1030 Vienna, Austria. ${ }^{3}$ Current address: Baxter Innovations GmbH, A-Wagramer Str. 17-19, Vienna 1221, Austria.

Received: 6 February 2014 Accepted: 19 June 2014

Published: 24 June 2014

\section{References}

1. Vaz FM, Wanders RJA: Carnitine biosynthesis in mammals. Biochem J 2002, 361:417-429.

2. Strijbis K, Vaz F, Distel B: Enzymology of the carnitine biosynthesis pathway. IUBMB Life 2010, 62(5):357-362.

3. Tanphaichitr V, Broquist HP: Role of lysine and N-trimethyllysine in carnitine biosynthesis. J Biol Chem 1973, 248(6):2176-2181.

4. Ramsay RR, Gandour RD, van der Leij FR: Molecular enzymology of carnitine transfer and transport. Biochim Biophys Acta Protein Struct Mol Enzymol 2001, 1546(1):21-43.

5. Kerner J, Hoppel C: Fatty acid import into mitochondria. Biochem Biophys Acta Mol Cell Biol Lipids 2000, 1486(1):1-17.

6. Mingrone G: Carnitine in type 2 diabetes. Ann N Y Acad Sci 2004, 1033:99-107.

7. DeFronzo RA: Pharmacologic therapy for type 2 diabetes mellitus. Ann Intern Med 1999, 131(4):281-303.

8. Wu P, Inskeep K, Bowker-Kinley MM, Popov KM, Harris RA: Mechanism responsible for inactivation of skeletal muscle pyruvate dehydrogenase complex in starvation and diabetes. Diabetes 1999, 48(8):1593-1599.

9. Brunner S, Kramar K, Denhardt DT, Hofbauer R: Cloning and characterization of murine carnitine acetyltransferase: evidence for a requrement during cell cycle progression. Biochem J 1997, 322:403-410.

10. van der Leij FR, Huijkman NCA, Boomsma C, Kuipers JRG, Bartelds B: Genomics of the human carnitine acyltransferase genes. Mol Genet Metab 2000, 71(1-2):139-153.

11. Zammit VA, Ramsay RR, Bonomini M, Arduini A: Carnitine, mitochondrial function and therapy. Adv Drug Deliv Rev 2009, 61(14):1353-1362.

12. Noland RC, Koves TR, Seiler SE, Lum H, Lust RM, Ilkayeva O, Stevens RD, Hegardt FG, Muoio DM: Carnitine insufficiency caused by aging and overnutrition compromises mitochondrial performance and metabolic control. J Biol Chem 2009, 284(34):22840-22852. 
13. Power RA, Hulver MW, Zhang JY, Dubois J, Marchand RM, Ilkayeva O, Muoio DM, Mynatt RL: Carnitine revisited: potential use as adjunctive treatment in diabetes. Diabetologia 2007, 50(4):824-832.

14. Muoio DM, Noland RC, Kovalik J-P, Seiler SE, Davies MN, DeBalsi KL, Ilkayeva OR, Stevens RD, Kheterpal I, Zhang J, Covington JD, Bajpeyi S, Ravussin E, Kraus W, Koves TR, Mynatt RL: Muscle-Specific Deletion of Carnitine Acetyltransferase Compromises Glucose Tolerance and Metabolic Flexibility. Cell Metabolism 2012, 15(5):764-777.

15. Godarova A, Litzlbauer E, Brunner S, Agu A, Lohninger A, Hofbauer R: $\mathrm{L}$-Carnitine regulates mRNA expression levels of the carnitine acyltransferases - CPT1A, CPT2 and CRAT. Chem Mon 2005, 136:1349-1363.

16. Rakhshandehroo M, Sanderson LM, Matilainen M, Stienstra R, Carlberg C, de Groot PJ, Müller M, Kersten S: Comprehensive Analysis of PPARalphaDependent Regulation of Hepatic Lipid Metabolism by Expression Profiling. PPAR Research 2007, 2007(26839):1-13.

17. Tachibana K, Kobayashi Y, Tanaka T, Tagami M, Sugiyama A, Katayama T, Ueda C, Yamasaki D, Ishimoto K, Sumitomo M, Uchiyama Y, Kohro T, Sakai J, Hamakubo T, Kodama T, Doi T: Gene expression profiling of potential peroxisome proliferator-activated receptor (PPAR) target genes in human hepatoblastoma cell lines inducibly expressing different PPAR isoforms. Nuclear Receptor 2005, 3(1):1-17.

18. Janssens V, Van Hoof C, De Baere I, Merlevede W, Goris J: Functional analysis of the promoter region of the human phosphotyrosine phosphatase activator gene: Yin Yang 1 is essential for core promoter activity. Biochem J 1999, 344(Pt 3):755-763.

19. Janssens V, Van Hoof C, De Baere I, Merlevede W, Goris J: The phosphotyrosyl phosphatase activator gene is a novel p53 target gene. J Biol Chem 2000, 275(27):20488-20495.

20. Hofer-Litzlbauer E: Biochemical and genetical consequences of carnitine deficiency caused by downregulation of the carnitine acyltransferase genes. In Doctoral Thesis. Vienna: Medical University of Vienna; 2005.

21. Cook GA, Edwards TL, Jansen MS, Bahouth SW, Wilcox HG, Park EA: Differential Regulation of Carnitine Palmitoyltransferase-I Gene Isoforms (CPT-I alpha and CPT-Ibeta) in the Rat Heart. J Mol Cell Cardiol 2001, 33(2):317-329.

22. Barrero MJ, Camarero N, Marrero PF, Haro D: Control of human carnitine palmitoyltransferase II gene transcription by peroxisome proliferatoractivated receptor through a partially conserved peroxisome proliferator-responsive element. Biochem J 2003, 369(3):721-729.

23. Dayoub R, Groitl P, Dobner T, Bosserhoff AK, Schlitt H-J, Weiss TS: Foxa2 (HNF-3[beta]) regulates expression of hepatotrophic factor ALR in liver cells. Biochem Biophys Res Commun 2010, 395(4):465-470.

24. Li JL, Wang QY, Luan HY, Kang ZC, Wang CB: Effects of L-carnitine against oxidative stress in human hepatocytes: involvement of peroxisome proliferator-activated receptor alpha. J Biomed Sci 2012, 19:32.

25. Gerondaes P, Alberti GMM, Loranne A: Fatty acid metabolism in hepatocytes cultured with hypolipidaemic drugs. Biochem J 1988, 253:161-167.

26. Ide T, Shimano H, Yoshikawa T, Yahagi N, Amemiya-Kudo M, Matsuzaka T, Nakakuki M, Yatoh S, lizuka Y, Tomita S, Ohashi K, Takahashi A, Sone H, Gotoda T, Osuga J, Ishibashi S, Yamada N: Cross-Talk between Peroxisome Proliferator-Activated Receptor (PPAR) alpha and Liver X Receptor (LXR) in Nutritional Regulation of Fatty Acid Metabolism. II. LXRs Suppress Lipid Degradation Gene Promoters through Inhibition of PPAR Signaling. Mol Endocrinol 2003, 17(7):1255-1267.

27. Roche T, Hiromasa Y: Pyruvate dehydrogenase kinase regulatory mechanisms and inhibition in treating diabetes, heart ischemia, and cancer. Cell Mol Life Sci 2007, 64(7):830-849.

28. Consoli A: Role of liver in pathophysiology of NIDDM. Diabetes Care 1992, 15(3):430-441.

29. Alesci S, De Martino MU, Mirani M, Benvenga S, Trimachi F, Kino T, Chrousos GP: L-Carnitine: a nutritional modulator of glucocorticoid receptor functions. FASEB J 2003, 17(11):1553-1555.

30. Siu FKY, Lee LTO, Chow BKC: Southwestern blotting in investigating transcriptional regulation. Nat Protoc 2008, 3(1):51-58.

doi:10.1186/1471-2164-15-514

Cite this article as: Kienesberger et al:: L-carnitine and PPARa-agonist fenofibrate are involved in the regulation of Carnitine Acetyltransferase (CrAT) mRNA levels in murine liver cells. BMC Genomics 2014 15:514.

\section{Submit your next manuscript to BioMed Central and take full advantage of:}

- Convenient online submission

- Thorough peer review

- No space constraints or color figure charges

- Immediate publication on acceptance

- Inclusion in PubMed, CAS, Scopus and Google Scholar

- Research which is freely available for redistribution 